\title{
Bread quality improvement by means of selected pregelatinized waxy rice flour (PWRF)
}

\author{
Shihang Yang1, Peiyi Cheng1, Litang Wang ${ }^{2}$, Shenchung Lin ${ }^{3}$, Chiching Yang ${ }^{1 *}$, Tzuching Wang ${ }^{4 *}$ \\ ${ }^{1}$ Department of Food Science and Technology, National Pingtung University of Science and Technology, Pingtung, Taiwan, ${ }^{2}$ Department \\ of Electrical Engineering, National Central University, Taoyuan, Taiwan, ${ }^{3}$ Department of Travel Management, Taipei University of Marine \\ Technology, Danshui Town, New Taipei, Taiwan, ${ }^{4}$ Department of Hospitality Management, Meiho University, Pingtung, Taiwan
}

\section{A B S T R A C T}

\begin{abstract}
The objective of the present study was attempted to develop a pregelatinized waxy rice flour (PWRF) retarding agent formulation by merging with $\alpha$-amylase and monoglycerides, as well as using pregelatinizing and lyophilizing technologies to improve bread characteristics such as staling and retrogradation. The major methods, including texture profile analysis (TPA) and sensory evaluation were employed to assess bread qualities. Research results demonstrated the amylose complexing index (ACl) of the PWRF-adding bread samples were higher than that of groups $\alpha$-amylase-adding, monoglycerides-adding and control. PWRF-adding bread samples exhibited higher starch digestibility and water activity (aw) and showed softer texture, lower hardness and soluble starch content than the groups $\alpha$-amylaseadding, monoglycerides-adding and control after storage. The PWRF-D exhibited the best effect among all formulations. Further, either fresh or after storage PWRF-adding bread samples acquired the higher sensory score. The bread qualities were improved by PWRF and the staling and retrogradation were further retarded.
\end{abstract}

Keywords: Bread; Pregelatinized waxy rice flour (PWRF); Staling; Retrogradation; Sensory evaluation

\section{INTRODUCTION}

Bread is a digestible and nutritious food and in some selected area it is adopted as staple food and is consider as appropriate food. During storage, like many foods made from starch, bread can be easily retrogradate and cause crystallization again. Del-Rosario and Pontiveros (1983) reported that from soft to hard of texture may curtail the storage life and lower product value. For all starchy foods, including bread, retrogradation is a definite phenomenon (Kweon et al., 1994). Thus, the bread quality can be extremely affected and therefore restrict its popularization and adoption (Huang et al., 1988). As the reason, to exploit new technologies to decline starch retrogradation is very important for bread industry.

Many techniques to improve starchy foods' quality and delay retrogradation were found by researchers such as the addition of selected starch (Huang et al., 1988), emulsifier (Rao et al., 1992) or enzyme (Kweon et al., 1994). For emulsifier, it can effectively prolong starch colloid hardening and defer staling and retrogradation rate (Keetels et al., 1996). Many emulsifiers are applied on starchy foods until today. Rao et al. (1992) declared that excellent efficiency of using amylose-lipid and its high capability to delay starch retrogradation. The ability of monoglycerides, one of emulsifiers, can delay starch staling effectively (Hibi, 2001).

Besides, $\alpha$-amylase can induce starch dehydration thus postpone staling and retrogradation was found (Kweon et al., 1994). Although $\alpha$-amylase could be postpone bread staling, excessive dose of $\alpha$-amylase may produce numerous soluble dextrin and cause the organization easy to form hollow and gummy (Hibi, 2001). Pregelatinized starch can as well ameliorate bread texture and decrease the bread volume and specific volume simultaneously though it must be careful to dominate the amount when use (Hibi, 2001). In our previous pre-experiment, use only $\alpha$-amylase or monoglycerides just exhibit slight effect on inhibiting staling and improving product texture. Considering these issues, we employed and slightly modified our previous study (Wang et al., 2011) which used PWRF to investigate the PWRF whether can be used in bread manufacture and attempt to improve the bread quality.

\footnotetext{
${ }^{*}$ Corresponding author:

Tzuching Wang, Department of Hospitality Management, Meiho University, Pingtung, 91202, Taiwan. E-mail: tcw0511@gmail.com Chiching Yang, Department of Food Science and Technology, National Pingtung University of Science and Technology, Pingtung, Taiwan. Email: yangcc.tw@gmail.com
} 


\section{MATERIALS AND METHODS}

\section{Ingredients and reagents}

High-gluten flour purchased from Uni-President Enterprises Corporation (Tainan, Taiwan). Monoglycerides was obtained from Yih-Yuan Food Additives Chemical Industrial Co., LTD. (Taipei, Taiwan). Waxy rice flour and indica rice flour were taken from Ping-Tung Foods Corporation (Pingtung, Taiwan). The approximate composition of waxy rice flour and indica rice flour were $80.8 \%$ and $77.4 \%$ for carbohydrate, $12.7 \%$ and $12.8 \%$ for moisture, $0.3 \%$ and $0.6 \%$ for crude protein, $5.6 \%$ and $8.2 \%$ for crude fat as well as $0.6 \%$ and $1.0 \%$ for ash, respectively. $\alpha$-Amylase (activity: 46500-48830 RAU/g) and yeast were bought from DSM Bakery Ingredients (Delft, Netherlands). All other food ingredients were food grade. Potassium sodium (+)-tartrate tetrahydrate, iodine, and acetic acid were purchased from Nacalai tesque (Kyoto, Japan). Potassium tartrate-water was acquired from Nakarai chemicals (Tokyo, Japan). Amylose (A-0512), and 3,5-Dinitrosalicylic acid were received from Sigma-Aldrich Inc. (St Louis, MO, USA). Hydrochloric acid and potassium iodine were got from Nihon Shiyaku (Osaka, Japan). Methyl alcohol (methanol) was received from Tedia Company Inc. (Fairfield, Ohio, USA).
Termamyl 120L type LS was gained from Novozymes Co., (Copenhagen, Denmark). Sodium hydroxide sodium acetate (anhydrous) was purchased from Union Chemical Works Ltd., (Hsinchu, Taiwan). All other regents were of analytical grade.

\section{Preparations of PWRF and bread samples Bread formulation and baking}

The materials and formulas of PWRF and bread samples are shown in Table 1 and 2, respectively. After mixing all materials, double volume of water was added and heated (temp.: $80^{\circ} \mathrm{C} /$ duration: $5 \mathrm{~min}$ ). Then, it was allowed to cool at room temperature (about $25^{\circ} \mathrm{C}$ ) and frozen $\left(-40^{\circ} \mathrm{C}\right)$ for three days and then lyophilized cake. Milled, crushed and sieved (100-mesh) lyophilized cake to obtain PWRF. For bread preparing, the indica rice flour was substituted by PWRF-A $\sim$ G (i.e. to produce bread $A \sim G$ ), added $20 \mathrm{mg} / \mathrm{kg}$ $\alpha$-amylase -amylase (i.e. to produce bread $\mathrm{H}$ ), and just added $0.3 \%$ monoglycerides (i.e. to produce bread I), respectively. The detailed preparation of bread is shown in Fig. 1.

\section{Bread weight, volume and specific volume}

The weight was measured after the bread loaves were removed from oven for $1 \mathrm{~h}$. The sesame seed displacement

Table 1: The materials and formulas of pregelatinized waxy rice flour

\begin{tabular}{lcccc}
\hline Formula & \multicolumn{4}{c}{ Pregelatinized waxy rice flour (PWRF) } \\
\cline { 2 - 5 } & Waxy rice flour $(\mathbf{g})$ & Water $(\mathbf{g})$ & ${\text { Monoglycerides }(\%)^{\mathbf{a}}}$ & $\boldsymbol{\alpha}$-Amylase (mg/kg) \\
\hline PWRF-A & 100 & 200 & 1 & 40 \\
PWRF-B & 100 & 200 & 2 & 40 \\
PWRF-C & 100 & 200 & 4 & 40 \\
PWRF-D & 100 & 200 & 4 & 40 \\
PWRF-E & 100 & 200 & 4 & 10 \\
PWRF-F & 100 & 200 & 4 & 20 \\
PWRF-G & 100 & 200 & 4 & 60 \\
\hline
\end{tabular}

${ }^{a}$ Monoglycerides was added at different levels (\%, flour basis). ${ }^{\mathrm{b}} \alpha$-amylase was added at different levels (mg/kg, flour basis)

Table 2: The materials and formulas of bread products

\begin{tabular}{|c|c|c|c|c|c|c|c|c|c|c|}
\hline \multirow[t]{2}{*}{ PWRF component } & \multicolumn{10}{|c|}{ Bread products } \\
\hline & Control & A & B & C & D & $\mathbf{E}$ & $\mathbf{F}$ & G & $\mathrm{Hb}$ & Ic \\
\hline Flour (g) & 100 & 97 & 97 & 97 & 97 & 97 & 97 & 97 & 100 & 100 \\
\hline Water (g) & 62 & 62 & 62 & 62 & 62 & 62 & 62 & 62 & 62 & 62 \\
\hline Butter (g) & 4 & 4 & 4 & 4 & 4 & 4 & 4 & 4 & 4 & 4 \\
\hline Salt (g) & 1.5 & 1.5 & 1.5 & 1.5 & 1.5 & 1.5 & 1.5 & 1.5 & 1.5 & 1.5 \\
\hline Sucrose (g) & 5 & 5 & 5 & 5 & 5 & 5 & 5 & 5 & 5 & 5 \\
\hline Yeast (g) & 1.5 & 1.5 & 1.5 & 1.5 & 1.5 & 1.5 & 1.5 & 1.5 & 1.5 & 1.5 \\
\hline PWRF-A $(g)^{a}$ & - & $3^{d}$ & - & - & - & - & - & - & - & - \\
\hline PWRF-B (g) & - & - & $3^{d}$ & - & - & - & - & - & - & - \\
\hline PWRF-C (g) & - & - & - & $3^{d}$ & - & - & - & - & - & - \\
\hline PWRF-D (g) & - & - & - & - & $3^{d}$ & - & - & - & - & - \\
\hline PWRF-E (g) & - & - & - & - & - & $3^{d}$ & - & - & - & - \\
\hline PWRF-F (g) & - & - & - & - & - & - & $3^{d}$ & - & - & - \\
\hline PWRF-G (g) & - & - & - & - & - & - & - & $3^{d}$ & - & - \\
\hline$\alpha$-Amylase (mg/kg) & - & - & - & - & - & - & - & - & 20 & - \\
\hline Monoglycerides (g) & - & - & - & - & - & - & - & - & - & 0.3 \\
\hline
\end{tabular}

a3\% (w/w flour basis) flour was replaced by PWRF-A G, respectively. ${ }^{\mathrm{b}} \alpha$-amylase was added at $20 \mathrm{mg} / \mathrm{kg}$, flour basis. ${ }^{\mathrm{b}} \mathrm{H}$ : Bread added $\alpha$-amylase directly

વ: Bread added monoglycerides directly. ${ }^{\text {: }}$ PWRF substituted ratios at $3 \%$ on volume. -: None add PWRF, $\alpha$-amylase or monoglycerides 
Yang, et al.: Bread quality improvement by PWRF

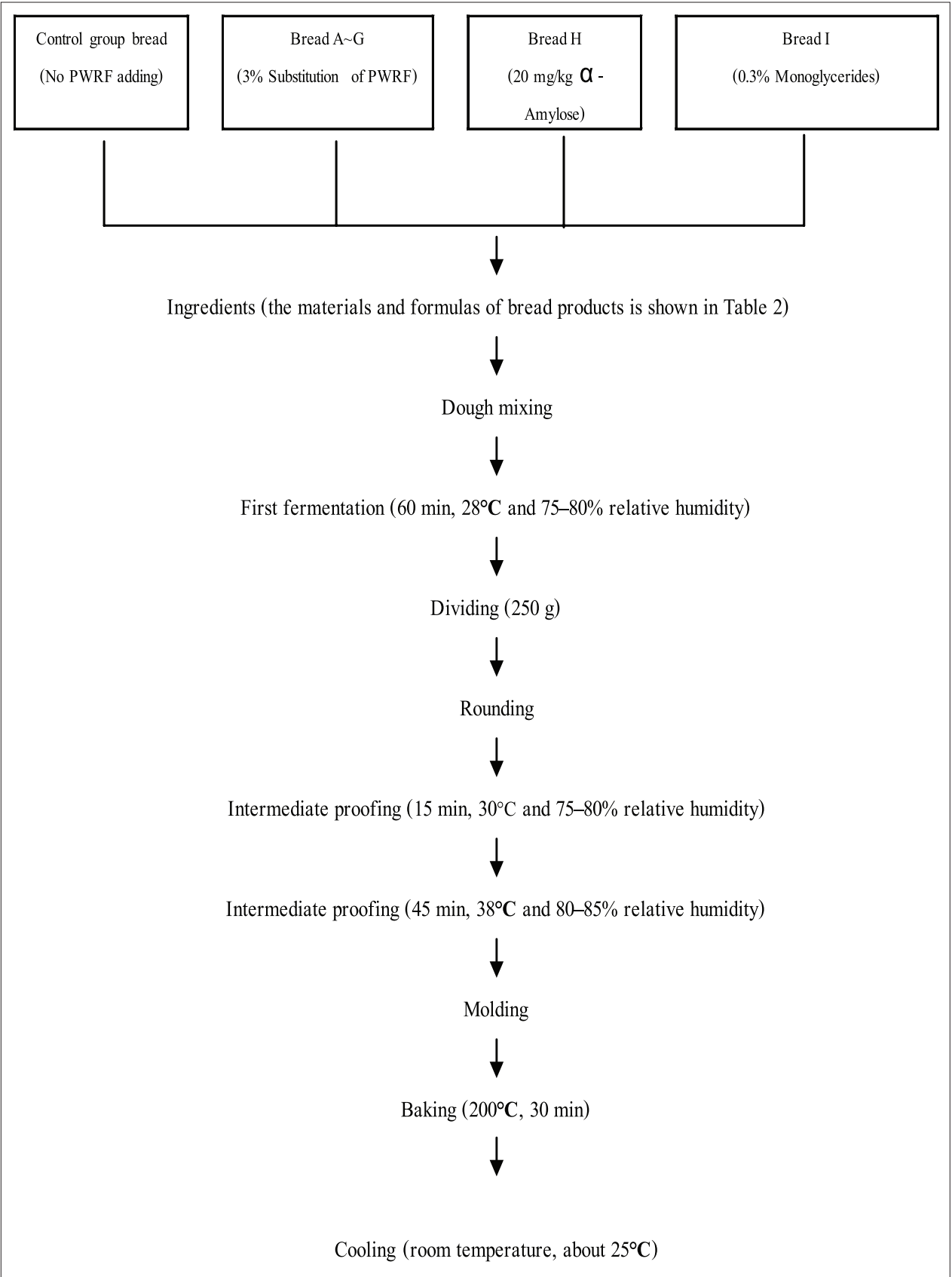

Fig 1. Flowchart of preparation of bread in the study.

method (Sangnark and Noomhorm, 2003) was employed to determine bread volume and the specific volume was measured by dividing the volume by bread weight.

\section{Properties analysis of PWRF and bread} Amylose complexing index (ACl)

The ACI value was determined according to Riisom et al. (1984).

\section{Soluble amylose content (SAC)}

The SAC was determined according to the method described by Shanthy et al. (1980).
Physical and chemical changes during storage

Bread samples were cooled for $3 \mathrm{~h}$ at room temperature and were packed in polyethylene and then sealed. These bread samples were symbolized respectively at selected days for analyzing various physical, chemical and sensory characteristics as described below.

\section{Moisture content and water activity (aw)}

During storage, the bread samples were examined for moisture content and aw on the selected day. For determination of moisture content, the procedure was followed by the AOAC method (AOAC. 1990). For 
detection of aw, bread samples was put in the sample case of CX-2 Water Activity Meter (Decagon Devices Inc., U.S.A.) and aw was determined at $25^{\circ} \mathrm{C}$.

\section{Texture profile analysis (TPA)}

TPA was executed by a universal materials testing machine (model: 5564, Instron, Canton, Ma, U.S.A). In brief, a diameter of $9 \mathrm{~mm}$ cylinder with a rate of $120 \mathrm{~mm} / \mathrm{min}$ to compress the tested samples $(3 \mathrm{~cm} \times 3 \mathrm{~cm} \times 1.5 \mathrm{~cm})$ to $75 \%$ of their primeval altitude. The adaptor was repeated again to finish the measuring. The TPA parameters including hardness, cohesiveness, adhesiveness, springiness, gumminess and chewiness were estimated according to Fiszman et al. (1998). The staling rate was determined as (firmness, ${ }_{\text {aging }}$ sample - firmness, fresh sample $) \times 100 \%$ (Maleki, 1981).

\section{Starch digestibility}

The starch digestibility was exercised according to Holm et al. (1985).

\section{Soluble starch content}

The soluble starch content was determined according to the report by Kim and D' Appolonia (1977) and with some modifications. In brief, weighed dry bread sample $(2.5 \mathrm{~g})$ in a volumetric flask and added distilled water $(70 \mathrm{~mL})$ into. Then, shaken (70 rpm, $30 \mathrm{~min}$ ) the sample and centrifuged $\left(10400 \times g, 10 \mathrm{~min}, 25^{\circ} \mathrm{C}\right)$. The precipitate was leached and washed with distilled water $(40 \mathrm{~mL})$ twice. Clustered thrice filtrate and made up to $250 \mathrm{~mL}$, drew $50 \mathrm{~mL}$ into the flask (weight A) and added 3-times methanol into, covered with an aluminum lid and incubated in a water bath (temp.: $100^{\circ} \mathrm{C} /$ duration: $20 \mathrm{~min}$ ). Taken off the supernatant liquid and allowed to overnight and heated in an oven until to constant weight (weight B). The percentage of soluble starch was determined as $\{$ [(Weight B Weight A) $\times 5] / 2.5\} \times 100 \%$, and the retrogradation rate was determined as $[1-$ (soluble starch content, - soluble starch content, fresh sample $)] \times 100 \%$ (Del-Rosario and Pontiveros 1983).

\section{Sensory analysis}

Acceptance testing was employed to assess sensory evaluation. Fifteen skilled sensory panelists were trained to depict their sensory experiences and to give a score from 1 to 9 . Respectively, 1 means soft and 9 means firm for moistureness, 1 means strong and 9 means weak for firmness, 1 means good and 9 means poor for springiness, and 1 means like and 9 dislike for overall acceptability.

\section{Statistical analysis}

All the measurements were performed at least in triplicate and the average values with SD were plotted. The experimental data collected were executed using Duncun's test in SAS Version 8.1. The mean values and SD were shown in the final results. The $P<0.05$ was considered statistical significance.

\section{RESULTS AND DISCUSSION}

\section{$\mathrm{ACl}$ and SAC}

Bread staling could be decreased by addition of antistaling enzymes (Amigo et al., 2016) and their synergistic interactions with retarding agents to prevent staling was found (Giannone et al., 2016). The highest ACI (95.39\%) was found when PWRF-D added and the lowest (90.05\%) was added PWRF-A (Table 3). This result was the same as our previous report (Wang et al., 2011). Experimentally, the addition of $\alpha$-amylase resulted in only a slight increase in the ACI of PWRF. Interestingly, PWRF-C, E, F, G exhibited no significant distinction upon the addition of $\alpha$-amylase while both the PWRF-D and PWRF-A were the two extremes in the experiment.

The ACI value of the bread is positively correlated with the addition of PWRF. This is due to two different factors. Firstly, the combination of emulsifier and $\alpha$-amylase can successfully decrease retrogradation by enhancing the

Table 3: The ACl of various PWRF and bread products as well as the effect of PWRF substituted ratios at $3 \%$ on volume, weight and specific volume of bread products

\begin{tabular}{|c|c|c|c|c|c|c|}
\hline \multicolumn{4}{|c|}{ Amylose complexing index $(\mathrm{ACl}, \%)$} & \multicolumn{3}{|c|}{ Bread products } \\
\hline \multicolumn{2}{|c|}{$\begin{array}{l}\text { Pregelatinized waxy rice flour } \\
\text { (PWRF) }\end{array}$} & \multicolumn{2}{|c|}{ Bread products } & \multirow{2}{*}{$\begin{array}{c}\text { Bread volume }(\mathrm{mL}) \\
1138^{\mathrm{a}}\end{array}$} & \multirow{2}{*}{$\begin{array}{c}\text { Bread weight }(\mathrm{g}) \\
217.9^{\mathrm{a}}\end{array}$} & \multirow{2}{*}{$\begin{array}{c}\text { Specific volume }(\mathrm{mL} / \mathrm{g} \\
5.22^{\mathrm{a}}\end{array}$} \\
\hline & & Control & $49.65^{\mathrm{e}}$ & & & \\
\hline PWRF-A & $90.05^{c}$ & A & $58.21^{\text {bcd }}$ & $1150^{\mathrm{a}}$ & $218.6^{a}$ & $5.26^{\mathrm{a}}$ \\
\hline PWRF-B & $91.51^{\mathrm{bc}}$ & $\mathrm{B}$ & $63.39^{\mathrm{ab}}$ & $1159^{a}$ & $222.1^{\mathrm{a}}$ & $5.22^{\mathrm{a}}$ \\
\hline PWRF-C & $94.66^{\mathrm{ab}}$ & $\mathrm{C}$ & $64.78^{\mathrm{ab}}$ & $1171^{\mathrm{a}}$ & $225.3^{\mathrm{a}}$ & $5.20^{\mathrm{a}}$ \\
\hline PWRF-D & $95.39^{a}$ & $\mathrm{D}$ & $66.24^{a}$ & $1158^{a}$ & $220.9^{a}$ & $5.24^{\mathrm{a}}$ \\
\hline PWRF-E & $92.24^{\mathrm{abc}}$ & $E$ & $58.62^{\mathrm{bcd}}$ & $1151^{a}$ & $219.0^{a}$ & $5.26^{a}$ \\
\hline PWRF-F & $93.24^{\mathrm{abc}}$ & $\mathrm{F}$ & $62.51^{\mathrm{abc}}$ & $1141^{a}$ & $217.5^{\mathrm{a}}$ & $5.25^{a}$ \\
\hline \multirow[t]{3}{*}{ PWRF-G } & $94.91^{\mathrm{ab}}$ & $\mathrm{G}$ & $61.33^{a b c}$ & $1134^{a}$ & $218.5^{a}$ & $5.19^{a}$ \\
\hline & & $\mathrm{H}$ & $55.18^{\text {cde }}$ & $1148^{a}$ & $218.6^{a}$ & $5.25^{a}$ \\
\hline & & I & $53.37^{\text {de }}$ & $1141^{a}$ & $216.8^{a}$ & $5.27^{a}$ \\
\hline
\end{tabular}

${ }^{a-e}$ Means with the different letter inside column are different significantly $(p<0.05)$ 
ACI. Secondly, the synthesis of amylose-lipid complex could delay the rate of recrystallization. Caballero et al. (2007) reported that the addition of $\alpha$-amylase can serve a dual purpose - increase the ACI value and exhibit antistaling effect for bread quality. The ACI value slightly increased with increased $\alpha$-amylase content of PWRFadded bread samples though there were no significant $(P>0.05)$ difference among bread sample groups $\mathrm{A}, \mathrm{B}$ and $C$ or among bread sample groups B, C and D. Further, the ACI value of those PWRF-added bread samples are significant $(P<0.05)$ higher than the control $(49.65 \%)$ and among them the group D bread had the highest ACI value $(66.24 \%)$. Groups B, C, F and G exhibited no significant $(P>0.05)$ difference, but their ACI values were significant $(P<0.05)$ higher than that of control and group A bread (58.21\%). In addition, the ACI value of groups B, C and G were significant $(P<0.05)$ higher than groups $\mathrm{H}$ and $\mathrm{I}$. This is primarily due to the possible correlation between ACI and PWRF. Matsukura et al. (1983) pointed out that the higher the formation of the complex, the higher the ACI, and hence, the more efficacious for postponing staling. Among seven PWRF groups, no significant $(P>0.05)$ difference of SAC was found (Fig. 2A); however, the SAC of PWRF-added bread samples were significant $(P<0.05)$ lower than that of control (Fig. 2B). The reason could result from that they possessed higher ACI values than that of control. Besides, it is also be due to that complexes frame an insoluble film on the starch appearance to avoid water soaking in starch particle and prevent further swelling. This phenomenon will hence reduce SAC and amylose exudation (Richardson et al., 2003).

\section{Bread weight, volume and specific volume}

Table 3 shows the weight, volume and specific volume of all breads. No significant $(P>0.05)$ difference with regard to weight, volume and specific volume among all bread samples. This result is in accordance with the previous research (Shu et al., 1999).

\section{Moisture content, aw, hardness, staling rate and retrogradation rate}

Berglund and Shelton (1993) reported that bread containing lower amount of moisture content could have more staling rate than the bread which containing higher amount of moisture content. Table 4 depicts the variances of moisture content, aw, hardness, staling and retrogradation rate during storage of bread samples. The moisture content of fresh breads was about $38.08-40.46 \%$, and no significant $(P>0.05)$ differences were found among all bread samples. This result from the present experiment is similar to Kulp and Ponte (1981). A decreasing tendency of moisture content was observed during storage. This decrease in moisture content was primarily due to evaporation and redistribution. Evaporation of water, though not the main

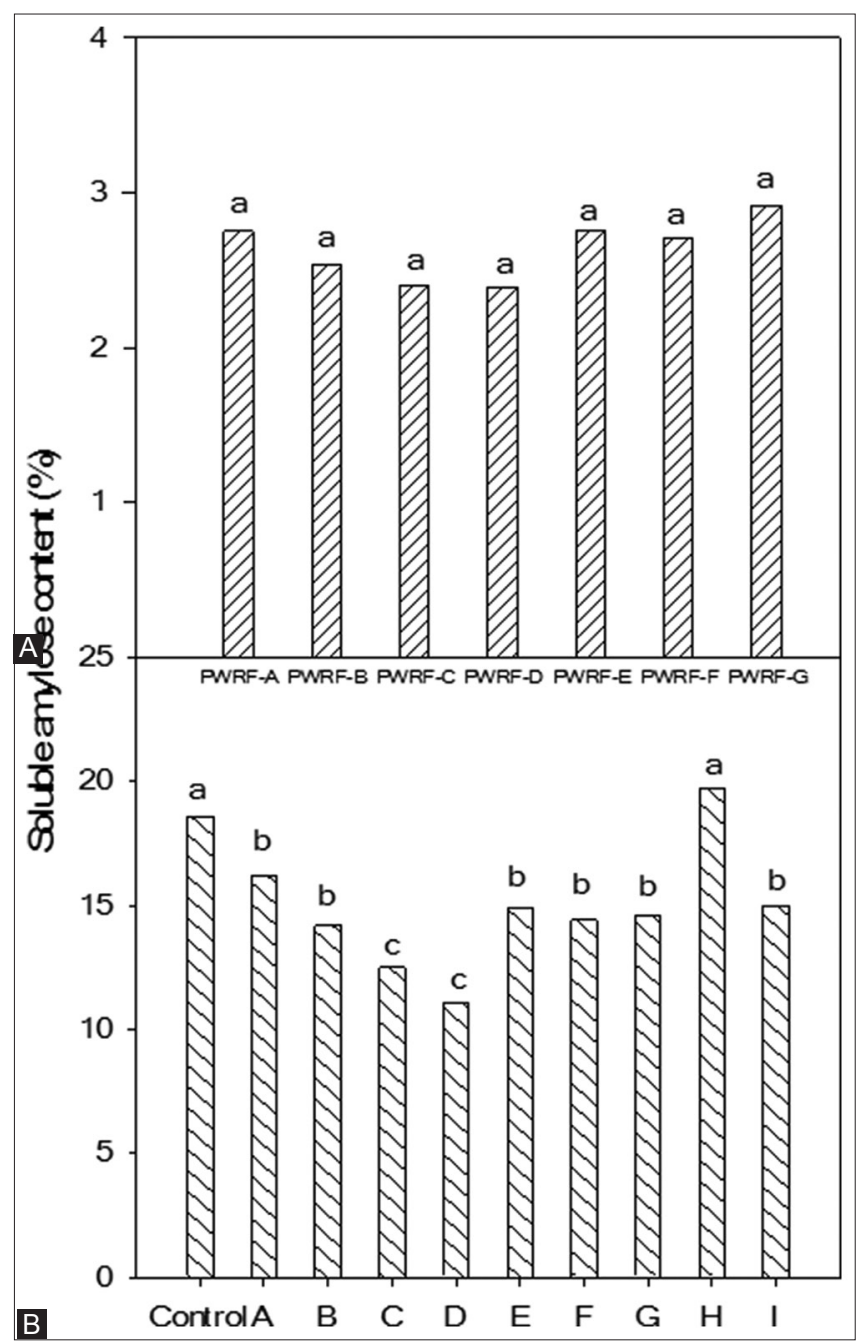

Fig 2. Soluble amylose content of pregelatinized waxy rice flour (PWRF) (A) and bread products (B). A G: Bread containing PWRF$A \sim G$, respectively. $H$ : Bread added $\alpha$-amylase directly. I: Bread added monoglycerides directly. Bars with different superscript letters $(\mathrm{a} \sim \mathrm{C})$ indicate significant differences $(P<0.05)$.

reason of staling, can still largely affect the staling rate of bread. For bread, it means that the higher the moisture content the lower the staling rate. In the current study, bread samples containing PWRF (groups $A \sim G$ ) which had a higher moisture content level, showed a lower staling rate. The aw of the bread will gradually decrease with the storage time. However, the addition of PWRF can not only increase the binding water, but also constrain the reduction aw of bread during storage, therefore delaying staling. A reasonable inference is the free water can fuse with hydrophilic substances, such as starch, in the bread (Sidhu et al., 1997). Czuchajowska and Pomeranz (1989) revealed the mechanism of the reduction of aw in bread central and the increasing of surface aw after three days storage and concluded that it was due to the moisture transport from interior to exterior. 
Yang, et al.: Bread quality improvement by PWRF

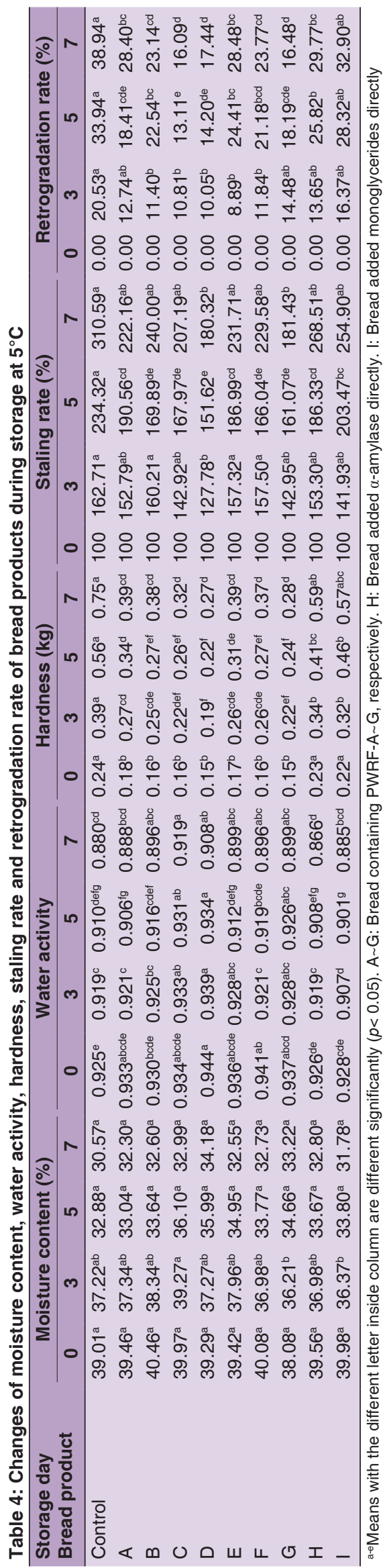

On baking foods, emulsifier can not only make texture better but also inhibit retrogradation rebirth. For bread; however, emulsifier can be used as bread improver, dough conditioner and enhancer, thereby improving the bread quality. The bread physico-chemical properties could be improved by adding suitable additive during storage (Curti et al., 2016). Also, the bread staling process was found to be affected by some selected parameter characteristic (Lapćík et al., 2016). In the present study, it was found that PWRF can also softening bread and does so much more effectively than only use $\alpha$-amylase or monoglycerides. Staling causes the texture losing and reduces eating quality were proved by Ji et al. (2007). The retrogradation is considered the major factor of staling; and further, the staling has intimate relevance to hard texture in bread (Krog et al., 1989). As shown in Table 4, staling rate of PWRF-added bread samples were lower than the control, and as expect the group D bread had the lowest staling rate. On the other hand, although group $G$ bread also had the second lowest staling rate, it possesses damp and sticky properties which result in difficult to be cut. Emulsifier can effectively temporize the hardness of starch colloid and extend retrogradation and staling rate during storage (Keetels et al., 1996). Based on the results, the best bread improver and anti-staling additive is the PWRF-D.

The starch retrogradation can also accompany with increase of enzyme hydrolysis (Ring et al., 1988). Amylose-lipid complexes can decrease starch retrogradation and restrain the intra-action among amylose particles (Zobel, 1973). In this study, the retrogradation of the control group was increased means that it has the largest staling after storage. On the other hand, the retrogradation of bread sample groups $A \sim G$ were lower than groups $H, I$ and control, which means that PWRF could efficiently inhibit retrogradation during storage.

\section{Starch digestibility, SAC and soluble starch content}

The starch digestibility decreases with the storage time (Fig. 3). The higher absorbance means the lower staling. The PWRF-added breads have higher starch digestibility than the control and group I bread after storage. This result implies that bread staling can decrease starch digestibility and the staling could be inhibited by adding PWRF. The starch digestibility of group $\mathrm{H}$ bread is also higher than the control and group I bread. This is probably due to the effect of $\alpha$-amylase. Jeang et al. (1990) also emphasized that starch digestibility of rice curd was decreased with the refrigeration time.

Kim and D'Appolonia (1977) reported that the increase of hardness and recrystallization may result from retrogradation. We also pointed that the degree of retrogradation and emulsifier could influence the SAC 


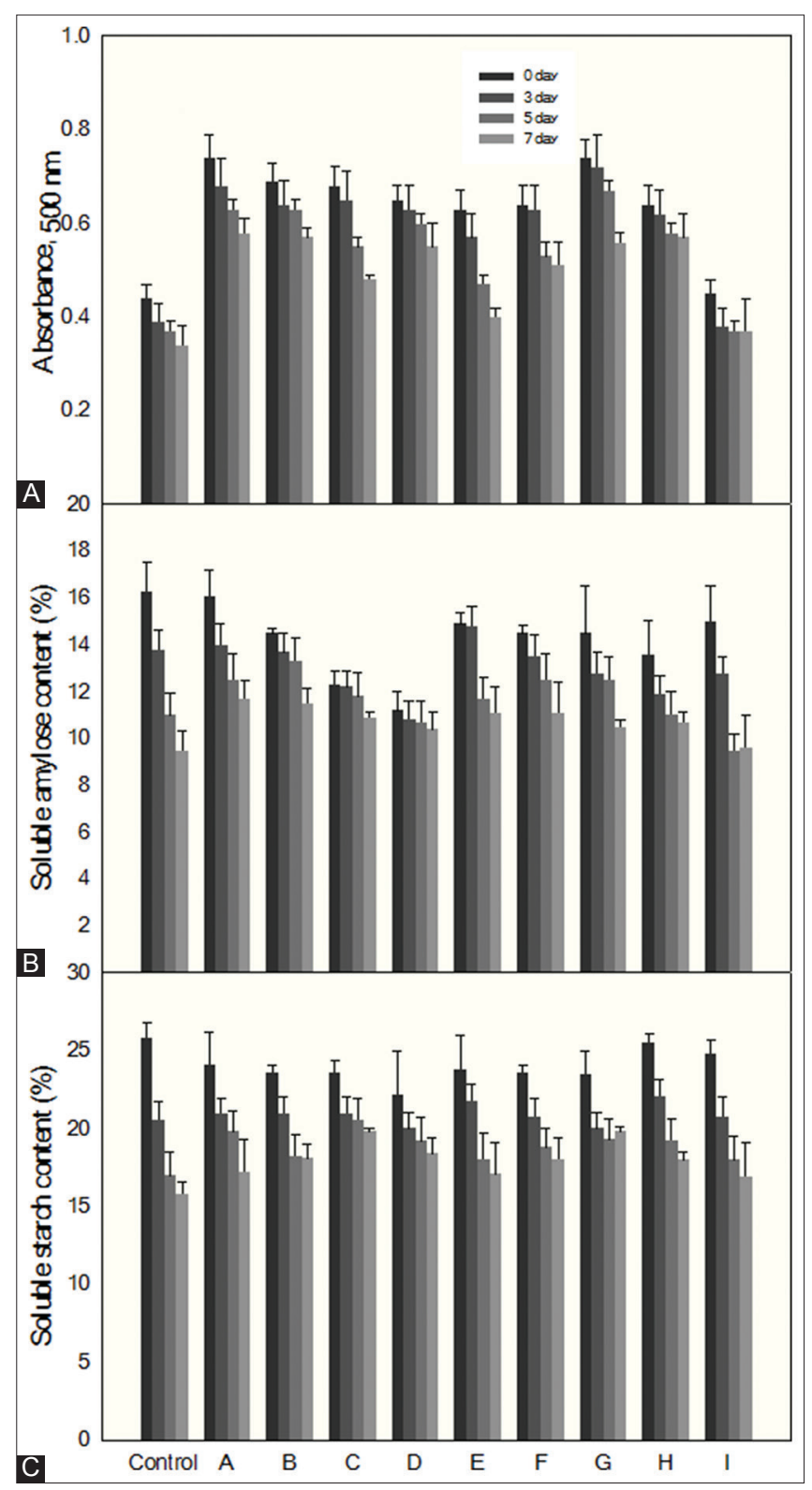

Fig 3. Changes in starch digestibility (A), amylose content (B) and soluble starch content $(\mathrm{C})$ of breads during storage at $5^{\circ} \mathrm{C}$. A G: Bread containing PWRF-A G, respectively. $\mathrm{H}$ : Bread added $\alpha$-amylase directly. I: Bread added monoglycerides directly.

(Wang et al., 2011). The starch staling is considered to be related with these phenomena. Even though higher retrogradation results in lower soluble amylose, the emulsifier could inhibit retrogradation. In the present experiment, the control group had the largest SAC followed by group I bread. The SAC was slightly decreased after storage. This is similar as the observation made by Schoch and French (1947).

Sidhu et al. (1997) described that the reduction of SAC and soluble starch was resulted from retrogradation and re-crystallization. Soluble starch content also decreased with storage time and this phenomenon obtained from our study is similar to the previous report (Huang et al., 1988). The control, groups $\mathrm{H}$ and I bread have higher decreasing ratio than others.

\section{TPA ANALYSIS RESULT}

TPA analysis result is shown in Fig. 4. No significant $(P>$ 0.05 ) differences of springiness was found among groups $B$, C, E, F, H, I and the control during storage; however, the springiness of groups $\mathrm{D}$ and $\mathrm{G}$ were significant $(P<0.05)$ higher than the control (Fig. 4A). Regarding cohesiveness, no significant $(P>0.05)$ differences was observed between PWRF-added breads and the control, except groups $\mathrm{H}$ and I. Both results of springiness and cohesiveness are in agreement with the report of Curti et al. (2014). Giannone et al. (2016) also reported that added $\alpha$-amylase could slow down chewiness change during storage period. Fig. 3B illustrates that groups $\mathrm{H}$ and I were significant $(P<0.05)$ lower than the other PWRF-added groups. The group $G$ bread had the highest adhesiveness (Fig. 4C) because of its damp and sticky property as mentioned above. With regard to gumminess, the control had the highest gumminess (0.15kg) followed by groups $\mathrm{H}$ and I, but the lowest values were observed in those PWRF-added breads (Fig. 4D). The control also had the highest chewiness values $(1.60 \mathrm{~kg} \times$ $\mathrm{mm})$, followed by groups $\mathrm{H}(1.42 \mathrm{~kg} \times \mathrm{mm})$ and I $(1.39 \mathrm{~kg}$ $\times \mathrm{mm}$ ), but the lower values were found in those PWRFadded breads (Fig. 4E). The springiness, cohesiveness and adhesiveness of all bread samples were decreased with storage time (Fig. 4A, 4B and 4C). On the contrary, the gumminess, and chewiness of all bread samples were increased with storage time (Fig. 4D and 4E). These results were in accord with Caballero et al. (2007).

\section{Sensory properties}

Fig. 5 radar chart shows the sensory properties of four selected groups, i.e. control, D, H and I, which could on behalf of all bread samples. For fresh bread samples, the firmness of group D bread was lower than the control, groups $\mathrm{H}$ and I (Fig. 5A). Group D bread had the highest springiness, chewiness and moistness; however, no significant $(P>0.05)$ differences were found among all bread samples. As anticipated, the group D bread also had the highest overall acceptability score after five-day storage (Fig. 5B). Group D bread not only possessed softer texture but also had better springiness and moistness. On the contrary, the control group had a damp and sticky texture which results in a defect in springiness and chewiness. Opposed to group D the control group had the lowest overall acceptability score due to its decrease in firmness and increase in springiness and moistness. Gómez et al. (2007) noticed that addition of hydrocolloid could effectively improve the yellow layer cakes sensory 


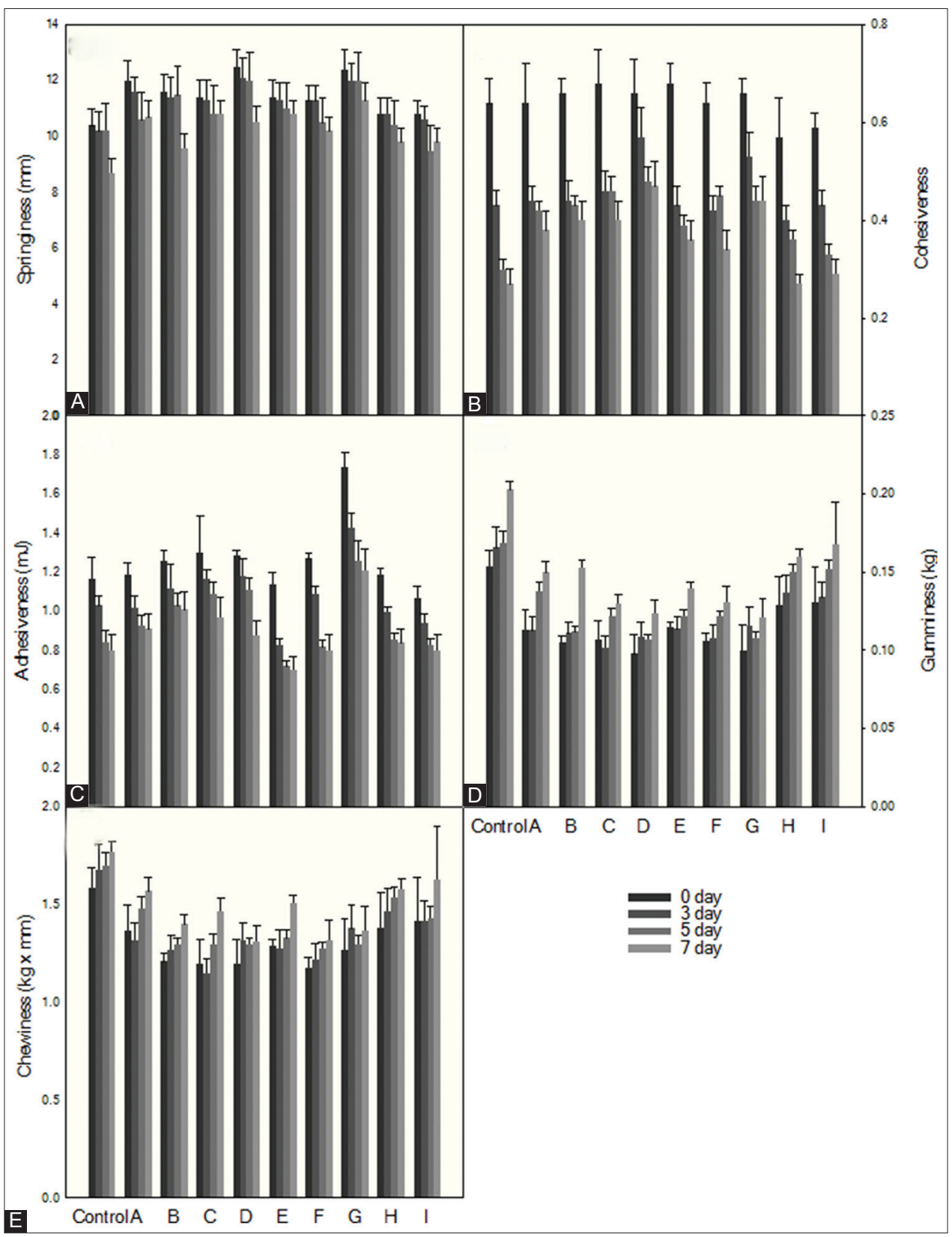

Fig 4. Changes in the springiness $(A)$, cohesiveness $(B)$, adhesiveness $(C)$, gumminess $(D)$ and chewiness $(E)$ of breads during storage at $5^{\circ} \mathrm{C}$. A G: Bread containing PWRF-A G, respectively. H: Bread added $\alpha$-amylase directly. I: Bread added monoglycerides directly.

evaluation. Based on these research advocates and our findings, the PWRF-D significantly improves bread's texture, springiness, moistness, chewiness and overall acceptability score regardless of fresh or after storage.

\section{CONCLUSION}

In many Western countries, the bread is considered the one of the most important food and when it is 'fresh' is the best time to consume; here 'fresh' means it can be maintained under the initial product status. Unfortunately, both the staling and retrogradation are the major disturbs for bread and many starchy foods. Regardless the water loss may escapes into the atmosphere or absorbed by the crust (Monteau et al., 2017), both can diminished the bread qualities and commodity value. Concerning bread qualities, to develop anti-staling formation and postpone retrogradation were very important jobs. Adding suitable additions in starch is considered to be simple and necessary method in this stage. In the present study, we merged $\alpha$-amylase and monoglycerides, and by pregelatinizing and lyophilizing technologies to develop PWRF retarding agent, as well as to analyze chemical and physical qualities of bread samples with different levels of substitution of 
Yang, et al.: Bread quality improvement by PWRF

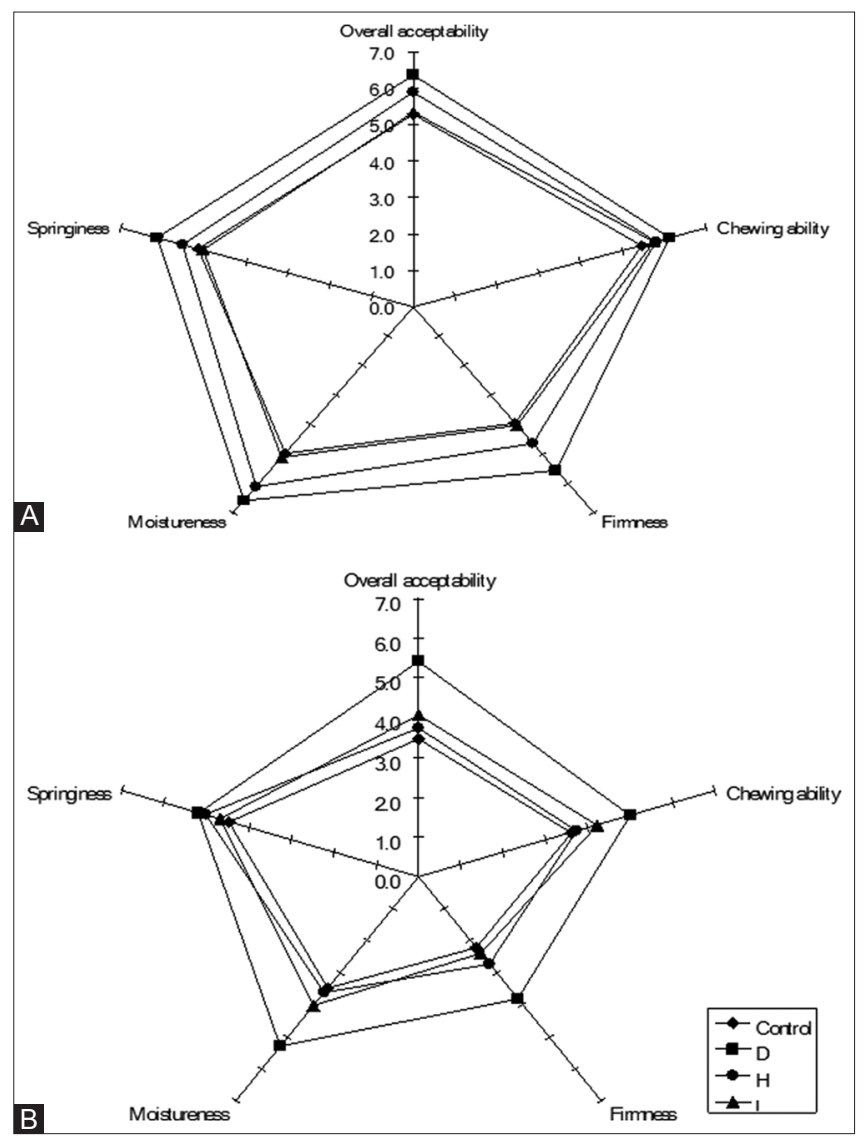

Fig 5. Sensory evaluation of breads with and without (control) different retarding agents before $(\mathrm{A})$ and after $(\mathrm{B})$ five days storage. D: Bread containing PWRF-D. H: Bread added $\alpha$-amylase directly. I: Bread added monoglycerides directly.

PWRF. The results indicated that PWRF is an effective improvement for bread qualities and the addition of PWRF-D obtain the best sensory acceptability. The PWRF certainly acted a crucial role in decelerating the staling and retrogradation of bread. Based on our findings, bread qualities can be improved significantly by means of PWRF and it seems is a suitable alternative method for processing high quality bread.

\section{Author contributions}

Yang S. and Cheng P. contributed equally to conduct the experiment and analyzed the results. Wang L. and Lin S. assisted in data analysis. Yang C. designed the experiment and prepared materials. Wang T. designed the experiment, wrote the manuscript and commented by all authors.

\section{REFERENCES}

Amigo, J. M., A. O. Alvarez, M. M. Engelsen, H. Lundkvist and S. B. Engelsen. 2016. Staling of white wheat bread crumb and effect of maltogenic a-amylases. Part 1: Spatial distribution and kinetic modeling of hardness and resilience. Food Chem. 208: 312-325
AOAC. 1990. Method 925.09. In: Official Methods of Analysis, $15^{\text {th }}$ ed Association of Official Analytical Chemists, Arlington, VA.

Berglund, P. T. and D. R. Shelton. 1993. Effect of frozen storage duration on firming properties of breads baked from frozen doughs. Cereal Foods World. 38(2): 89-90, 92-93.

Caballero, P. A., M. Gómez and C. M. Rosell. 2007. Improvement of dough rheology, bread quality and bread shelf-life by enzymes combination. J. Food Eng. 81(1): 42-53.

Curti, E., E. Carini, A. Diantom and E. Vittadini. 2016. The use of potato fibre addition in bread contributed to reduce bread staling. Food Chem. 195: 64-70.

Curti, E., E. Carini, G. Tribuzio and E. Vittadini. 2014. Bread staling: Effect of gluten on physico-chemical properties and molecular mobility. LWT Food Sci. Technol. 59(1): 418-425.

Czuchajowska, Z. and Y. Pomeranz. 1989. Differential scanning calorimetry, water activity and moisture contents in crumb center and near-curst zones of bread during storage. Cereal Chem. 66(4): 305-310.

Del-Rosario, R. R and C. R. Pontiveros. 1983. Retro-gradation of some starch mixtures. Starch Stärke. 35(3): 86-92.

Fiszman, S. M., M. Pons and M. H. Damasio. 1998. New parameters for instrumental texture profile analysis: Instantaneous and retarded recoverable springiness. J. Food Text. Stud. 29(5): 499-508.

Giannone, V., M. R. Lauro, A. Spina, A. Pasqualone, L. Auditore, I. Puglisi and G. Puglisi. 2016. A novel $\alpha$-amylase-lipase formulation as anti-staling agent in durum wheat bread. LWT Food Sci. Technol. 65: 381-389.

Gómez, M., F. Ronda, P. A. Caballero, A. Blanco and C. M. Rosell. 2007. Functionality of different hydrocolloids on the quality and shelf-life of yellow layer cakes. Food Hydrocol. 21(2): 167-173.

Hibi, Y. 2001. Effects of selected surfactants on amylopectin recrystallization and on recoverability of bread crumb during storage. Starch Stärke. 53(5): 227-234.

Holm, J., I. Björck, N. G. Asp, L. B. Siöberg and I. Lundguist. 1985 Starch availability in vivo after flaking, steam-cooking and popping of wheat. J. Cereal Sci. 3(3): 193-206.

Huang, R. M., J. M. Tsiang and C. Y. Lii. 1988. The effect of sodium stearoyl 2-lactylateon the staling rate of Fon-Pen cake. Food Sci. 15(3): 287-295.

Jeang, C. L., S. J. Wu and T. C. Lin. 1990. Effects of treatments of different additive on the texture of frozen rice curd. J. Agric. Forestry. 39(2): 145-155

Ji, Y., K. Zhu, H. Qian and H. Zhou. 2007. Staling of cake prepared from rice flour and sticky rice flour. Food Chem. 104(1): 53-58.

Keetels, C. J. A. M., T. Van-Vliet, A. Jurgens and P. Walstra. 1996. Effects of lipid surfactants on the structure and mechanics of concentrated starch gels and starch bread. J. Cereal Sci. 24(1): 33-45.

Kim, S. K. and B. L. D’Appolonia. 1977. Bread staling studies. II. Effect of protein content and storage temperature on the role of starch. Cereal Chem. 54: 216-219.

Krog, N., S. K. Olesen, H. Tørnæs and T. Jønsson. 1989. Retrogradation of the starch fraction in wheat bread. Cereal Foods World. 34(3): 281-285.

Kulp, K. and J. G. Ponte. 1981. Staling of a white pan bread: Fundamental causes. Crit. Rev. Food Sci. Nutr. 15(1): 1-48.

Kweon, M. R., C. S. Park, B. M. Auh, N. S. Yang and K. H. Park. 1994. Phospholipid hydrolysate and,antistaling amylase effects on retrogradation of starch in bread. J. Food Sci. 59(5): 1072-1076.

Lapčík, L., M. Vašina, B. Lapčíková and T. Valenta. 2016. Study of 
bread staling by means of vibro-acoustic, tensile and thermal analysis techniques. J. Food Eng. 178: 31-38.

Maleki, M., J. L. Vetter and W. J. Hoover. 1981. The effect of emulsifiers, sugars, shortening and soya flour on the staling of Barbari flat bread. J. Sci. Food Agric. 32(12): 1209-1211.

Matsukura, U., A. Matsunaga and K. Kainuma. 1983. Structural studies of the retrogradation of gelatinized starch. J. Jpn. Soc. Starch Sci. 30(1): 106-109.

Monteau, J. Y., E. Purlis, E. Besbes, V. Jury and A. Le-Bail. 2017. Water transfer in bread during staling: Physical phenomena and modeling. J. Food Eng. 211: 95-103.

Rao, P. A., A. Nussinovitch and P. Chinachoti. 1992. Effects of selected surfactants on amylopectin recrystallization and on recoverability of bread crumb during storage. Cereal Chem. 69(6): 613-618.

Richardson, G., M. Langton, A. Bark and A. M. Hermansson. 2003. Wheat starch gelatinization-the effects of sucrose, emulsifier and the physical state of the emulsifier. Starch Stärke. 55(34): 150-161.

Riisom, T., N. Krog and J. Eriksen. 1984. Amylose complexing capacities of cis-and trans-unsaturated mono-glycerides in relation to their functionality in bread. J. Cereal Sci. 2(2): 105-118.
Ring, S. G., J. M. Gee, M. Whittam, P. Orford and I. T. Johnson. 1988. Resistant starch: Its chemical form in foodstuffs and effect on digestibility in vitro. Food Chem. 28(2): 97-109.

Sangnark, A. and A. Noomhorm. 2003. Effect of particle sizes on functional properties of dietary fibre prepared from sugarcane bagasse. Food Chem. 80(2): 221-229.

Schoch, T. J. and D. French. 1947. Studies on bread staling. I. The role of starch. Cereal Chem. 24: 231-249.

Shanthy, A. P., C. M. Sowbhagya and K. R. Bhattacharya. 1980. Simplified determination of water-insoluble amylose content of rice. Starch Stärke. 32(12): 409-411.

Shu, H. C., T. H. Huang, C. Y. Hsieh and T. T. Ku. 1999. Practical Bread Production Technology (in Chinese). China Grain Products Research and Development Institute, Taipei,. , pp. 349-366, 391-394.

Sidhu, J. S., J. Al-Saqer and S. Al-Zenki. 1997. Comparison of methods for the assessment of the extent of staling in bread. Food Chem. 58(1-2): 161-167.

Wang, T. C., S. C. Lin, Y. P. Shen, T. C. Wang-Mccall, K. P. Lan, M. H. Chin, P. Y. Cheng and C. C. Yang. 2011. Studies of retarding agent for decreasing starch retrogradation in Wan Kao (rice curd). J. Food Qual. 34(4): 268-277.

Zobel, H. F. 1973. A review of bread staling. Baker's Dig. 47: 52-61. 